\title{
Physiological response of three micropropagated plantlets of Rhododendron hybrids for heat stress
}

\author{
Elias G. Oba ${ }^{1,2}$, Jingfeng $\mathrm{Hu}^{3}$, Zhihui Zhang ${ }^{4}$, Shifeng $\mathrm{Li}^{1}$, Lvchun Peng ${ }^{1}$, Jihua Wang ${ }^{1}$ and Weijia Xie ${ }^{1}$ \\ ${ }^{1}$ Flower Research Institute of Yunnan Academy of Agricultural Science, National Engineering Research Center for \\ Ornamental Horticulture, Kunming, Yunnan, PR China \\ ${ }^{2}$ Ethiopian Institute of Agricultural Research, Addis Ababa, Ethiopia \\ ${ }^{3}$ Institute of Horticultural Crops of Yunnan Academy of Agricultural Science, Kunming, Yunnan, PR China \\ ${ }^{4}$ Institute of Medicinal Plants of Yunnan Academy of Agricultural Science, Kunming, Yunnan, PR China
}

\section{Summary}

As a result of global warming, heat stress has become the major challenge to plant growth and development. To avert this challenge, development of heat stress tolerant cultivars is the major way forward.

Here we evaluated the response of three Rhododendron hybrids ( $R$. 'XXL' $\times \boldsymbol{R}$. 'Jingle Bells', $R$. 'XXL' $\times$ $R$. 'Cosmopolitan', and $R$. 'XXL') to heat stress under control conditions.

Rhododendron in vitro plantlets were placed in a growth chamber at $38^{\circ} \mathrm{C}$ for 18 days and the plantlets were monitored at $0,3,6,12$ and 18 day for chlorophyll fluorescence parameters (Fv/Fm and F'v/F'm), SOD activity and proline content.

As exposure to high temperature duration prolonged, chlorophyll fluorescence parameters (Fv/Fm and $F^{\prime} v / F^{\prime} m$ ) decreased and in response to heat stress F'v/F'm showed more sensitivity than Fv/Fm. In addition, high temperature $\left(38^{\circ} \mathrm{C}\right)$ exposure could not induce significant SOD activity at different duration of exposure for all hybrids. Proline accumulation also observed at $6^{\text {th }}$ day of high temperature exposure only for $R$. 'XXL' as compared to non-stressed treatment.

Our work also showed the first attempt of using chlorophyll fluorescence imaging system to study heat stress response of in vitro raised Rhododendron. This study provides useful information for gene banks to screen large Rhododendron germplasm collections for heat stress tolerance.

Keywords

antioxidants, chlorophyll fluorescence, fluorescence imaging, photosynthesis, photosystem II (PSII) photochemistry, screening

\section{Introduction}

The genus Rhododendron is one of the largest in the family among Ericaceae and contains about 124 genera of which most species are popular woody ornamentals. The genus contains more than 1,000 species classified into eight subgenera (Cullen, 2005). Currently, more than 25,000 hybrids have been developed using the existed species diversity to improve ornamental traits (Krebs, 2018a). However, in order to combat the current challenges such as abiotic stress due to climate change, it is important to develop new Rhododendron cultivars that can maintain good ornamental quality under global challenges such as climate change.

\section{Significance of this study}

What is already known on this subject?

- Rhododendron is the most popular woody ornamental used as landscape plant around the world. Owing to climate change, heat stress has become the major limiting factor for Rhododendron production.

What are the new findings?

- Our work reported direct measurement of chlorophyll fluorescence from in vitro culture of Rhododendron using chlorophyll fluorescence imaging system in order to study perturbation due to heat stress.

What is the expected impact on horticulture?

- This has a potential to improve the efficiency of Rhododendron germplasm screening for abiotic stress at early stage and to reduce cost of breeding for better cultivars.

Nearly $1.0^{\circ} \mathrm{C}$ of global warming was recorded above pre-industrial levels due to global greenhouse gas emissions in 2017 and increasing $0.2^{\circ} \mathrm{C}$ per decade. It is also estimated that, if global greenhouse gas emissions continue to increase at the current rate, global warming is likely to reach $1.5^{\circ} \mathrm{C}$ between 2030 and 2052 (IPCC, 2018). This leads to increase in mean temperature in most land and ocean regions with devastating consequence for plant diversity and ecosystem (IPCC, 2018). Due to climate change, heat stress has become one of the major limiting factors for Rhododendron production and developing heat stress tolerant Rhododendron cultivar is the major way forward.

Heat stress occurs when the temperature surpass ambient temperature by $10-15^{\circ} \mathrm{C}$ (Wahid et al., 2007). It affects a wide range of structures and functions of cell and affects plant survival in so many ways. Heat stress may result in scorching of leaves and stems, leaf abscission and senescence; inhibition and damage of shoot, root as well as fruit, which lead to diminished plant productivity (Vollenweider and Günthardt-Goerg, 2005). High temperature also destroys the photosynthetic apparatus, caused membrane fluidity and altered homeostasis as well as the activities of carbon metabolism enzymes (Bita and Gerats, 2013). In order to mitigate effect of heat stress, plants developed tolerance mechanisms including accumulation of compatible solutes (e.g., Glycine betaine, proline) and protective proteins (e.g., heat shock proteins), and reactive oxygen species scavenging 
enzymes such as SOD, ascorbate peroxidase (APX), catalase (CAT), or antioxidants such as ascorbic acid or glutathione (Bita and Gerats, 2013; Waszczak et al., 2018). However, there are two major plant processes that are specifically venerable to heat stress, i.e., pollen development and photosynthesis. The photosynthetic apparatus is the most sensitive component affected by heat stress that leads to inactivation of photosystem II (PSII) and disorganization of thylakoid membrane (Baker and Rosenqvist, 2004; Mathur and Jajoo, 2014). As a result, $\mathrm{CO}_{2}$ assimilation and electron transport are interrupted and this phenomenon can be detected using chlorophyll fluorescence parameters (Fv/Fm and $\mathrm{F}^{\prime} \mathrm{v} / \mathrm{F}^{\prime} \mathrm{m}$ ) that have been widely used to identify cultivars tolerant to heat stress (Baker and Rosenqvist, 2004).

There are numerous studies on abiotic stress tolerance in Rhododendron. For instance, drought tolerance (Lipp and Nilsen, 1997; Cordero and Nilsen, 2002; Cai et al., 2014, 2019), cold tolerance (Anisko and Lidstrom, 1996; Marian et al., 2004). Compared with other abiotic stresses, however only a few reported the effect of heat stress on Rhododendron. Currently, $R$. hyperythrum and $R$. obtusum identified as heat stress tolerant and could be used for breeding program (Ranney et al., 1995; Fang et al., 2017; Krebs, 2018b). Moreover, external application of the combined salicylic acid and $\mathrm{CaCl}_{2}$ also showed enhanced heat stress tolerance of $R$. 'Fen Zhen Zhu' (Shen et al., 2016).

However, most works related to heat stress experiment are mainly conducted on pot-grown Rhododendron (Ranney et al., 1995; Shen et al., 2016, 2017; Fang et al., 2017; Krebs, $2018 \mathrm{~b}$ ), which consumes time and resources. In order to develop a cultivar that combines high ornamental quality, heat tolerance, disease resistant character, it is important to search new approaches that enable screening and comparison of available germplasm rapid and simple. Rhododendron is a woody perennial plant that has long breeding cycles; therefore development of improved cultivars resistant to biotic and abiotic stresses may require many breeding cycles and years (Van Nocker and Gardiner, 2014). To reduce breeding cycles for rapid cultivar development, tissue culture-based in vitro selection and germplasm screening method is a feasible and cost-effective tool for developing stress tolerant plants (Rai et al., 2011). Nevertheless, there is no previous work related to tissue culture based in vitro comparison or screening of Rhododendron for heat stress tolerance.

In this work, we followed a new approach to compare Rhododendron hybrids under heat stress. We used tissue cultures based in vitro Rhododendron plantlets together with chlorophyll fluorescence imaging system as a rapid, nondestructive, and noninvasive screening tool. To supplement this, we also used physiological parameters such as antioxidant (SOD) activity and compatible osmolytes (proline). Therefore, the aim of this research was to compare the physiological response of three new Rhododendron hybrids (Rhododendron 'XXL' $\times$ Rhododendron 'Jingle Bells', and Rhododendron 'XXL' $\times$ Rhododendron 'Cosmopolitan', Rhododendron ' $\mathrm{XXL}$ ') to heat stress in vitro.

\section{Materials and methods}

\section{Plant material and treatments}

To compare high temperature response, three in vitro plantlets of Rhododendron hybrids (Rhododendron 'XXL' $\times$ Rhododendron 'Jingle Bells', and Rhododendron 'XXL' $\times$ Rhododendron 'Cosmopolitan' and Rhododendron 'XXL') were obtained from Flower Research Institute, Kunming, China.
Plantlets then multiplied and finally transferred to rooting media (WPM + $0.75 \mathrm{mg} \mathrm{L}^{-1} \mathrm{NAA}+1.5 \mathrm{mg} \mathrm{L}^{-1} \mathrm{IBA}+$ sugar $30 \mathrm{~g} \mathrm{~L}^{-1}+6 \mathrm{~g} \mathrm{~L}^{-1}$ Agar) at $25^{\circ} \mathrm{C}$, and $16 \mathrm{~h}$ light $/ 8 \mathrm{~h}$ dark and $60 \%$ humidity.

To resume the heat stress experiment, Rhododendron plantlets were transferred to growth chamber and exposed to $38^{\circ} \mathrm{C}$ heat stress, on which each treatment contains three replications and each replication represented by two jars each with 10 plantlets. Observations as well as data collection were made on $0,3,6,12$, and 18 days for fluorescence, SOD activity, proline content.

\section{Chlorophyll fluorescence measurement}

Chlorophyll fluorescence was measured on in vitro platelets directly from culture vessel after 30 min of dark adaptation using FluorImager chlorophyll fluorescence imaging system (Technologica Ltd., Colchester, U.K.). Minimum fluorescence (Fo) was measured during the weak measuring pulses, and maximum fluorescence (Fm) was measured during an 800-ms pulsed light exposure to a PPFD of $6,349 \mu \mathrm{mol} \mathrm{m}{ }^{-2} \mathrm{~s}^{-1}$. The maximum photochemical efficiency of PSII (Fv/Fm) was calculated using the experimentally determined Fo and Fm, where Fv was the difference between Fo and $\mathrm{Fm}$. To determine $\mathrm{F}^{\prime} \mathrm{v} / \mathrm{F}^{\prime} \mathrm{m}$, in vitro plantlets were continuously illuminated with actinic light at intensity of $100 \mu \mathrm{mol}$ $\mathrm{m}^{-2} \mathrm{~s}^{-1}$ (which is equivalent to light intensity used for in vitro plantlets growth room) for about three minutes and saturating pulse of $6,349 \mu \mathrm{mol} \mathrm{m}^{-2} \mathrm{~s}^{-1}$ applied.

\section{Superoxide dismutase (SOD) activities}

The activity of superoxide dismutase (SOD) was measured according to Beauchamp and Fridovich (1971). Homogenizing $0.3 \mathrm{~g}$ of leaf tissue in $5 \mathrm{~mL}$ of extraction buffer [50 mM sodium phosphate buffer ( $\mathrm{pH} 7.0$ ), containing $0.1 \mathrm{mM}$ EDTA and 1\% (w/v) PVP] using a pre-chilled mortar and pestle on ice. The homogenate was centrifuged at $5,000 \mathrm{~g}$ for $30 \mathrm{~min}$ at $4^{\circ} \mathrm{C}$. The resulting supernatant was collected as a crude enzyme extract and assayed for the activity of superoxide dismutase (SOD). SOD activity was determined by measuring its ability to inhibit photochemical reduction of nitroblue tetrazolium (NBT). The $3 \mathrm{~mL}$ reaction mixture contained $50 \mathrm{mM}$ phosphate buffer (pH 7.8), $13 \mathrm{mM}$ Met, $2 \mathrm{mM}$ riboflavin, $100 \mathrm{mM}$ EDTA, $75 \mathrm{mM}$ NBT, and $100 \mu \mathrm{L}$ of enzyme extract. The reaction was started with the addition of riboflavin and carried out for 15 min under irradiance of $100 \mu \mathrm{mol}$ photons $\mathrm{m}^{-2} \mathrm{~s}^{-1}$ provided by $14 \mathrm{~W}$ white fluorescent lamp. A system devoid of enzymes served as a negative control. One unit of SOD activity was defined as the amount of enzyme required to cause $50 \%$ inhibition of the reduction of NBT when monitored at $560 \mathrm{~nm}$ using UV-VIS spectrophotometer (Helios Omega, U.K.).

\section{Proline content}

Free proline content was measured for the standard and the fresh leaves according to the procedure of Bates et al. (1973). Proline was extracted from $0.3 \mathrm{~g}$ of the leaves stored at $-80^{\circ} \mathrm{C}$ using $5 \mathrm{~mL}$ of $3 \%$-sulfosalicylic acid (w/v). Two milliliters of the extract were mixed with $2 \mathrm{~mL}$ of glacial acetic acid and $2 \mathrm{~mL}$ of acid-ninhydrin reagent in a test tube and incubated for $1 \mathrm{~h}$ at $100^{\circ} \mathrm{C}$. The reaction was then quickly stopped on ice before the addition of $4 \mathrm{~mL}$ of toluene then shaken very well for $30 \mathrm{~s}$ by hand. Samples were kept on table until it reached room temperature and were measured using UV-VIS spectrophotometer (Helios Omega, U.K.) at $520 \mathrm{~nm}$. 


\section{Statistical analysis}

The results were determined using ANOVA and experimental the data were the average values with \pm standard errors (SE) for six replicates for fluorescence and three replicates for SOD activity and proline content. Variation among the treatment means was compared using Tukey test and the data were found to be significant with $P$ value $<0.05$. All statistical analyses were performed using SPSS 16.0 software for Windows (SPSS Inc., Chicago, IL, U.S.A.) and graphical presentation, using Sigma plot version 10.0 (Systat Inc., San Jose, CA, U.S.A.).

\section{Results}

Chlorophyll florescence measurements of in vitro raised Rhododendron plantlets in response to heat stress

Chlorophyll fluorescence measurements were made on one-month old in vitro Rhododendron plantlets after $38^{\circ} \mathrm{C}$ heat exposure at $0,3,6,12$ and $18^{\text {th }}$ day. Maximum quantum yield of PSII photochemistry was calculated for both dark-adapted (Fv/Fm) and light-adapted (F'v/F'm) conditions. As heat stress duration prolonged, chlorophyll fluorescence parameters (Fv/Fm and F'v/F'm) gradually decreased (Figures 1 and 2). It was found that Fv/Fm was significantly affected at $18^{\text {th }}$ day for all the hybrids as compared to control $\left(0\right.$ day at $\left.25^{\circ} \mathrm{C}\right)$ (Figure 1$)$. Likewise, significant $(p<0.05)$ decrease of $\mathrm{Fv} / \mathrm{Fm}$ obtained at $12^{\text {th }}$ day of heat exposure for $R$. 'XXL' $\times R$. 'Jingle Bells' and $R$. 'XXL' as compared to control ( 0 day at $25^{\circ} \mathrm{C}$ ). On the other hand, we found no significant difference among hybrids at each duration of heat treatment. Moreover, beyond non-imaging fluorescence measurements, we also showed the photosynthetic heterogeneity of Rhododendron hybrids in response to heat stress (Figure 3). As the duration of heat stress exposure prolonged from $3^{\text {rd }}$ day to $18^{\text {th }}$ day, the spatial heterogeneity of fluorescence image of in vitro plantlets increased for three hybrids.

The quantum efficiency of photosystem II (PSII) was also

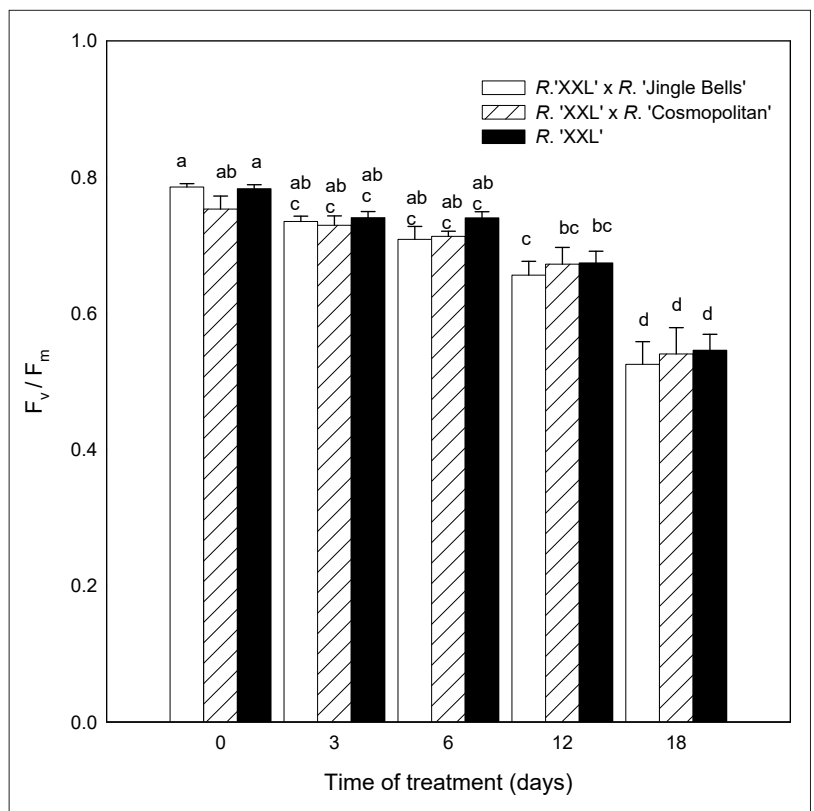

FIGURE 1. Estimation of maximum quantum yield of PSII $\left(\mathrm{F}_{\mathrm{v}}\right.$ $/ \mathrm{F}_{\mathrm{m}}$ ) on dark-adapted in vitro plantlets. Time of treatment 0 day is control at $25^{\circ} \mathrm{C}$. Data indicate the means \pm SE $(n=6)$. Different letters above the bars indicate significant differences $(P<0.05)$ by Tukey test across different duration. determined by the ratios of variable chlorophyll a fluorescence $\left(F^{\prime} v\right)$ to maximal chlorophyll a fluorescence $\left(F^{\prime} m\right)$ in light-adapted Rhododendron plantlets exposed to $38^{\circ} \mathrm{C}$ heat stress (Figure 2). There was significant decrease of F'v/F'm at $12^{\text {th }}$ and $18^{\text {th }}$ day as compared to control treatment (Figure 2). Whereas no significant difference was observed among hybrids at each heat exposure duration. For all the hybrids under heat stress condition, increase in duration of exposure associated with fall of both $\mathrm{Fv} / \mathrm{Fm}$ and $\mathrm{F}^{\prime} \mathrm{v} / \mathrm{F}^{\prime} \mathrm{m}$ and F'v/F'm is more sensitive than $\mathrm{Fv} / \mathrm{Fm}$ in identifying heat stress response.

\section{SOD activity of in vitro raised Rhododendron plantlets in response to heat stress}

The results depicted in Figure 4 show that the effects of heat stress on SOD activity of three Rhododendron hybrids. The SOD activities of the three hybrids were not significantly affected in response to heat stress at all duration of high temperature stress as compared to control $\left(0\right.$ day at $\left.25^{\circ} \mathrm{C}\right)$. Moreover, no significant SOD activity among hybrids at each time point were observed.

\section{Accumulation of proline in in vitro raised Rhododendron plantlets in response to heat stress}

The ability of three Rhododendron hybrids to accumulate osmolytes, such as free proline, under heat stress condition was investigated. Our result showed no significant difference $(p<0.05)$ among hybrids at all duration of heat stress exposure observed (Figure 5). Only the hybrid $R$. 'XXL' at $6^{\text {th }}$ day of heat stress accumulated significantly higher proline as compared to the control treatment. On the contrary, the proline content was not affected for $R$. 'XXL' $\times R$. 'Cosmopolitan' and $R$. 'XXL' $\times R$. 'Jingle Bells' at all duration of heat exposure.

\section{Discussion}

Currently, heat stress is becoming the global challenge driven by climate change and we are feeling its effect day to

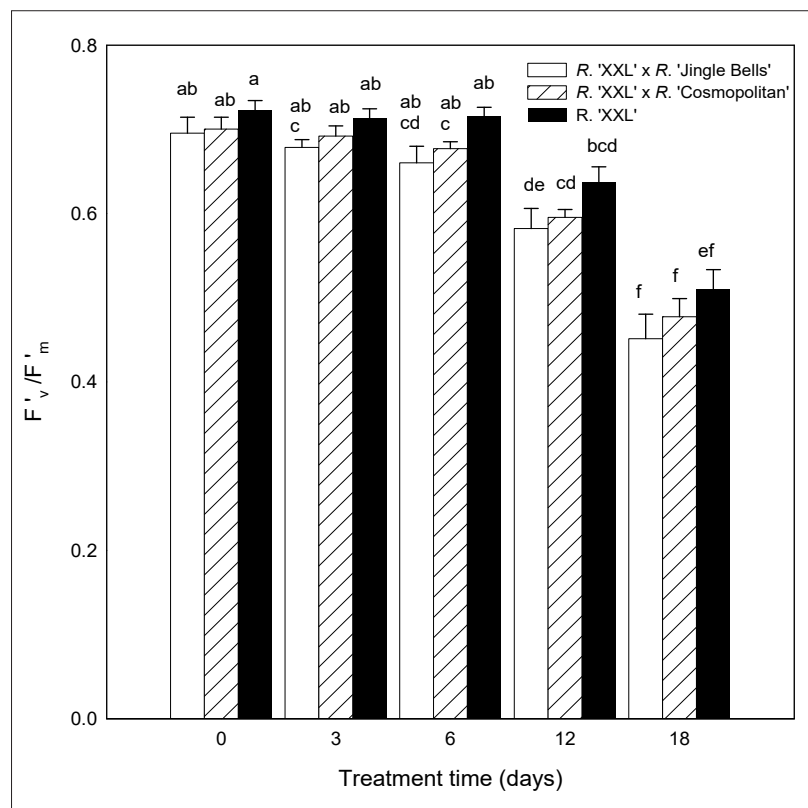

FIGURE 2. Estimation of maximum quantum yield of PSII $\left(\mathrm{F}_{\mathrm{v}} / \mathrm{F}_{\mathrm{m}}{ }_{\mathrm{m}}\right)$ on light-adapted in vitro plantlets. Time of treatment 0 day is control at $25^{\circ} \mathrm{C}$. Data indicate the means $\pm \operatorname{SE}(n=6)$. Different letters above the bars indicate significant differences $(P<0.05)$ by Tukey test across different duration. 


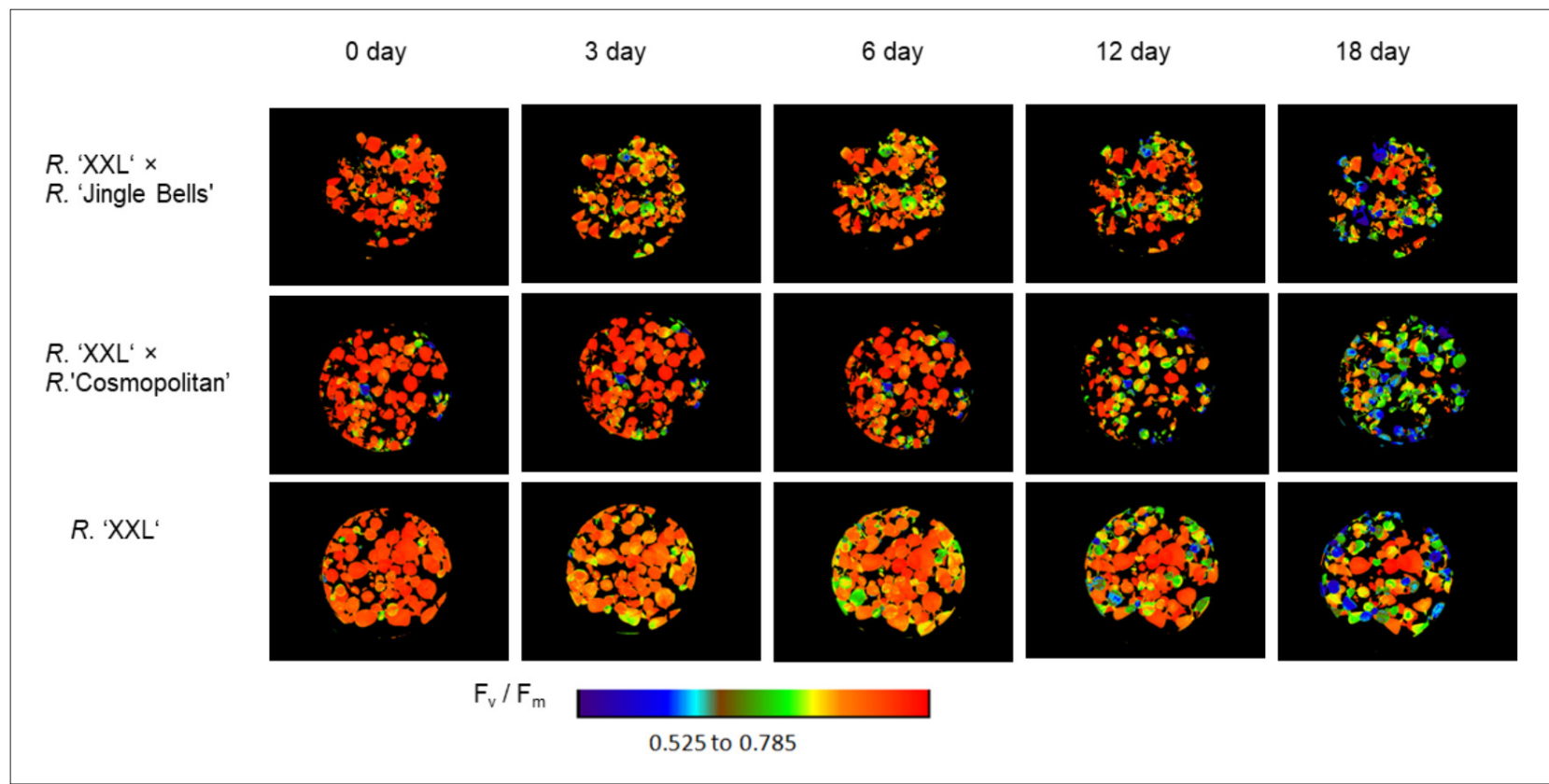

FIGURE 3. The effect of heat stress $\left(38^{\circ} \mathrm{C}\right)$ on the heterogeneity of photosynthetic performance of in vitro Rhododendron plantlets at different heat exposure periods.

day. However, due to their sessile nature, plants respond to change in temperature (Quint et al., 2016). High temperatures cause adverse effect on physiology and metabolism of plant cells and specifically reproductive development and photosynthesis are vulnerable (Wahid et al., 2007). In this work we measured chlorophyll fluorescence, SOD activity and proline accumulation to compare three one-month-old in vitro raised Rhododendron hybrids for heat stress $\left(38^{\circ} \mathrm{C}\right)$.

Chlorophyll fluorescence is an important tool to study plant performance and, together with imaging systems, it can serve to monitor plant health, and used as screening tool for

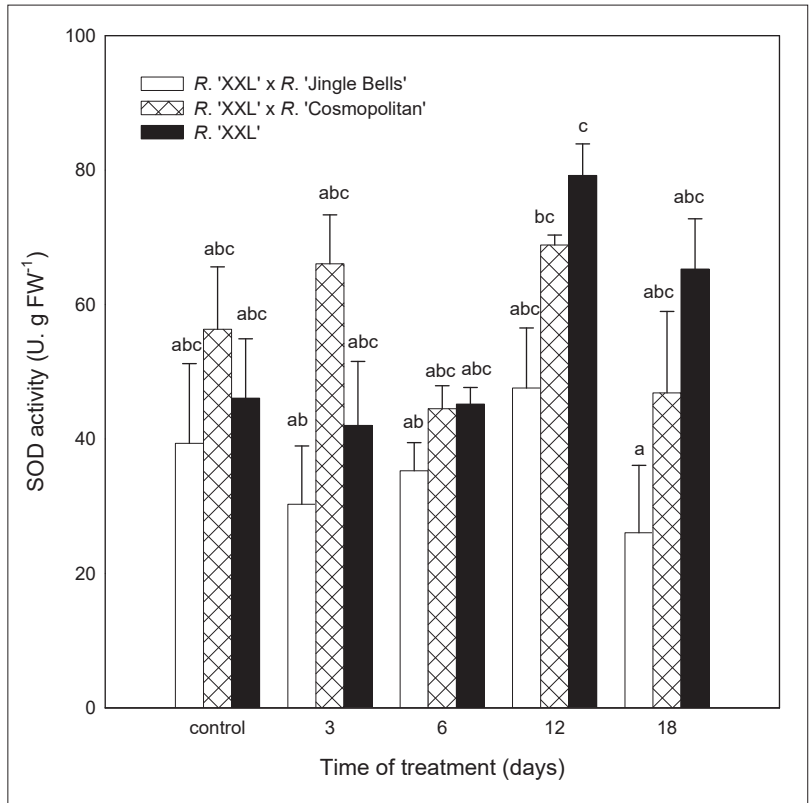

FIGURE 4. Estimation of SOD activity of in vitro plantlets of three hybrid $(R$. 'XXL', $R$. 'XXL' $\times R$. 'Iingle Bells', and $R$. 'XXL' × $R$. 'Cosmopolitan'), after exposure of $38^{\circ} \mathrm{C}$ temperature. Control shows 0 day at $25^{\circ} \mathrm{C}$. Data indicate the means $\pm \mathrm{SE}$ $(n=3)$. Different letters above the bars indicate significant differences $(P<0.05)$ by Tukey test across different duration. evaluating the physiological status of whole plants or individual leaves (Kalaji et al., 2016; Lawson and Vialet-Chabrand, 2018). The most important feature that it has is the ability to measure multiple plant materials simultaneously and to assess the spatial heterogeneity within plants or leaves (Oxborough, 2004; Lawson and Vialet-Chabrand, 2018). Therefore, measuring fluorescence is useful as it is a rapid, nondestructive, and noninvasive screening tool for plant performance under abiotic stress such as heat stress (Brestic and Zivcak, 2013). However, limited studies conducted on application of chlorophyll fluorescence on Rhododendron. For instance,

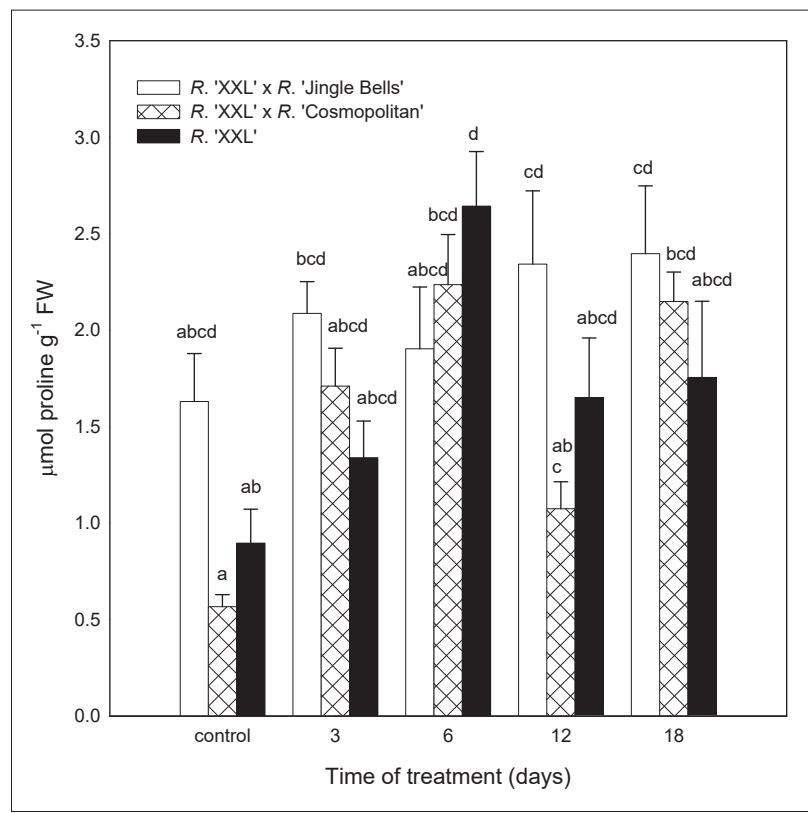

FIGURE 5. Estimation of proline content of in vitro plantlets of three hybrid ( $R$. 'XXL', $R$. 'XXL' $\times R$. 'Jingle Bells', and $R$. 'XXL' $\times$ $R$. 'Cosmopolitan'), after exposure of $38^{\circ} \mathrm{C}$ temperature. Control shows 0 day at $25^{\circ} \mathrm{C}$. Data indicate the means \pm SE $(n=3)$. Different letters above the bars indicate significant differences $(P<0.05)$ by Tukey test across different duration. 
Fang et al. (2017) compared four pot-grown Rhododendron cultivars for heat stress using chlorophyll fluorescence parameters such as Fo, Fv/Fm and F'v/F'm and found significant difference after three days of $38 / 35^{\circ} \mathrm{C}$ heat treatment and $\mathrm{Fv} / \mathrm{Fm}$ and $\mathrm{F}^{\prime} \mathrm{v} / \mathrm{F}^{\prime} \mathrm{m}$ decreased for three cultivars and Fo increased except heat tolerant cultivar. However, several studies applied chlorophyll fluorescence on in vitro raised plantlets for various reasons. Aitken-Christie et al. (1992) applied chlorophyll fluorescence on in vitro raised shoots of Pinus radiata as indicator of nutrient or physiological stress of shoots. Serret et al. (2001) studied whether photoautotrophic growing in vitro produced Gardenia jasminoides plantlets with less photoinhibition problems during acclimatization and reported gardenia plantlets cultured in vitro under conventional sucrose concentration showed less photoinhibition during acclimatization. Ibaraki and Matsumura (2005) used chlorophyll fluorescence parameter Fv/Fm to evaluate photosynthetic capacity of micropropagated potato plantlets and imaging as well as estimation of Fv/Fm was conducted from outside of the culture vessels. They found that average value of Fv/Fm was affected by sucrose content of the culture. In this work we used for the first time, FluorImager chlorophyll fluorescence imaging system (Technologica Ltd., Colchester, U.K.) to compare three one-month-old in vitro raised Rhododendron hybrids for heat stress $\left(38^{\circ} \mathrm{C}\right)$. In order to induce heat stress, Rhododendron in vitro plantlets were placed in a growth chamber at $38^{\circ} \mathrm{C}$ for 18 days and data for chlorophyll fluorescence parameters (Fv/Fm and $F^{\prime} v / F^{\prime} m$ ) were recorded at 0 day $\left(25^{\circ} \mathrm{C}\right)$ as control, 3 , $6,12,18$ day. Our result showed that Fv/Fm significantly affected at $18^{\text {th }}$ day of heat stress exposure for all the hybrids as compared to control ( 0 day at $25^{\circ} \mathrm{C}$ ). Moreover, significant difference obtained at $12^{\text {th }}$ day of heat exposure for $R$. 'XXL' $\times R$. 'Jingle Bells' and $R$. 'XXL' as compared to control (0 day at $25^{\circ} \mathrm{C}$ ). On the other hand, we found no significant difference among hybrids at each duration of heat treatment. It is well known that the measurement of Fv/Fm used to estimate the maximum quantum efficiency of photosystem II (PSII) photochemistry (Butler, 1978). It provides a measure of the health intactness of the photosynthetic apparatuses (PSII/ LHC complex) at any temperature. As a result any environmental perturbations will immediately cause a decrease in the value of Fv/Fm (Baker, 2008).

On the other hand, we found that there was significant decrease of $\mathrm{F}^{\prime} \mathrm{v} / \mathrm{F}^{\prime} \mathrm{m}$ at $12^{\text {th }}$ and $18^{\text {th }}$ day as compared to control treatment (Figure 2). This decrease Fv'/Fm' was due to heat stress damage on photosynthetic apparatus and this leads to more light harvest than actually needed for photochemistry. Therefore, the remaining excess energy dissipated as heat and measured as Fv'/Fm'. Whereas no significant difference was observed among hybrids at each heat exposure duration. For all the hybrids under heat stress condition, increase in duration of exposure associated with decrease of both Fv/ $\mathrm{Fm}$ and $\mathrm{F}^{\prime} \mathrm{v} / \mathrm{F}^{\prime} \mathrm{m}$ and the result also shows that $\mathrm{F}^{\prime} \mathrm{v} / \mathrm{F}^{\prime} \mathrm{m}$ is more sensitive than Fv/Fm in response to heat stress. Different researchers recommend measurements of Fv'/Fm' as potential for use in screening germplasm to identify high temperatures tolerance. Recently, similar result was reported up on evaluation of forty-four tomato (Solanum lycopersicum) lines originating from U.S.A. including three wild accessions under controlled conditions for heat tolerance and reported both Fv/Fm and Fv'/Fm' decreased in the heat-sensitive genotypes, but Fv'/Fm' was found to be a better predictor for heat-shock sensitivity (Hameed et al., 2015). Baker and Rosenqvist (2004) also recommended Fv'/Fm' as potential parameter that could be used to screen germplasm to identify high temperature tolerant genotype.

Fluorescence measurement instrument such as CFImager (Technologica Ltd., Colchester, U.K.) is a powerful tool that enables imaging chlorophyll fluorescence to detect perturbations of metabolism and map spatial heterogeneity of leaf photosynthetic performance (Baker and Rosenqvist, 2004; Baker, 2008). Our work showed that the heterogeneity of in vitro plantlets increased as duration of heat stress exposure prolonged from $3^{\text {rd }}$ day to $18^{\text {th }}$ day (Figure 3 ). Whereas, for control plantlets at 0 day $\left(25^{\circ} \mathrm{C}\right)$, high homogeneity was observed. This demonstrates the differences in photosynthetic performance among heat stress durations. Heterogeneity among heat stress durations and hybrids observed may be due to loss of PSII fluorescence yield as a result of inhibition of PSII electron transport that is created by inhibition of $\mathrm{NADH}$ and ATP consumption during carbon fixation (Baker, 2008). Our work also confirmed the fact that imaging chlorophyll fluorescence using CFImager can be used to detect heat stress response of in vitro Rhododendron platelets and enables monitoring this response on spatial heterogeneity. This paves a way for rapid evaluation of the performance of different Rhododendron cultivars in response to heat stress at early stage.

Heat stress causes over-accumulation of reactive oxygen species (ROS) in plant cells and mainly damages the repair system of PSII called the D1 protein (Theis and Schroda, 2016). This leads to reduction in plant growth, development, and productivity. Antioxidant enzymes such as SOD considered as the first line of defence used by plants to scavenge superoxide (Bita and Gerats, 2013). In the current study, SOD activity was not significant among hybrids at all duration in response to high temperature exposure. Even though the effect of heat stress on in vitro Rhododendron has not yet been reported, few research work was published on pot-grown Rhododendron. For instance, Shen et al. (2016) reported that SOD activity of pot-grown Rhododendron 'Fen Zhen Zhu' cultivar decreased under heat stress. Moreover, the same author also reported higher SOD activity on pot-grown heat sensitive Rhododendron cultivar ( $R$. 'Liu Qiu Hong'), than heat tolerant cultivar ( $R$. 'Lan Yin') (Shen et al., 2017). In contrast to the above result, Zhao et al. (2018) reported there was no significant increase when pot-grown $R$. hainanense were exposed to $25^{\circ} \mathrm{C}$ and $38^{\circ} \mathrm{C}$, but significant increase in SOD activity was recorded when the temperature increased from $35^{\circ} \mathrm{C}$ to $40^{\circ} \mathrm{C}$. Therefore, from the above results we can conclude that SOD activity in response to heat stress is highly dependent on genotype and growth stage of Rhododendron plants.

Proline is primary metabolites accumulating in response to heat stress in plants and it is vital to regulate osmotic activities and protect cellular structures from increased temperatures by maintaining the cell water balance, membrane stability, and by buffering the cellular redox potential (Bita and Gerats, 2013). Shen et al. (2017) compared two potgrown Rhododendron hybrids $R$. 'Lan Yin' (moderate heat tolerant) and $R$. 'Liu Qiu Hong' (heat-sensitive) and found decrease in proline content for both cultivars and specifically proline content decreased in heat-sensitive cultivar. The same author indicated that this decline in proline content in response to heat stress mainly occur due to the genetic difference existed between two cultivars. However, this result is in contradiction with ours in that as the duration exposure for high temperature prolonged, only the hybrid $R$. 'XXL' at $6^{\text {th }}$ day accumulated significantly higher proline as compared to the control treatment. On the contrary, the proline content 
was not affected for $R$. 'XXL' $\times$ R. 'Cosmopolitan' and $R$. 'XXL' $\times R$. 'Jingle Bells' at all durations of heat exposure. Moreover, no significant difference among hybrids at all durations of heat stress exposure was observed (Figure 5). Previous studies also demonstrated that as temperature increases proline accumulation also increased in response to heat shock on R. hainanense (Zhao et al., 2018). Proline accumulation in response to heat stress is controversial among plant scientists. For instance, proline accumulates significantly in response to heat stress and confers tolerance of tomato (Zhou et al., 2019; Raja et al., 2020), hybrid maize (Hussain et al., 2019) and lentil (Singh et al., 2019). On the contrary, heat stressed Arabidopsis plants could not accumulate proline (Rizhsky et al., 2004), and lower than normal amount of proline accumulated in germinating wheat seeds exposed to elevated temperature $35^{\circ} \mathrm{C}$ (Song et al., 2005). Similar findings were also observed in transgenic plants with altered expression of proline biosynthetic genes. For example, over expression of Arabidopsis P5CR (AtP5R) gene in soybean improved drought and heat stress (De Ronde et al., 2004). In contrast, tobacco plants constitutively over-expressing a gene for the proline biosynthetic enzyme $\Delta(1)$-pyrroline-5-carboxylate synthetase 1 gene significantly enhanced proline production in the transformant, but the plant became heat sensitive as compared to control (Dobra et al., 2010). Likewise, Arabidopsis plants ectopically expressing the $\Delta(1)$-pyrroline-5-carboxylate synthetase 1 gene (AtP5CS1) under the control of the HSP17.6II gene promoter had enhanced proline biosynthesis under heat stress conditions but a decreased thermotolerance (Lv et al., 2011). Therefore, proline accumulation in response to heat stress may be species dependent. The hybrids used in this experiment were also the result of crosses of different Rhododendron species and this might be the reason of observed fluctuation in biochemical response.

In conclusion, for all the hybrids under heat stress condition, increase in duration of exposure associated with fall of both $\mathrm{Fv} / \mathrm{Fm}$ and $\mathrm{F}^{\prime} \mathrm{v} / \mathrm{F}^{\prime} \mathrm{m}$ and $\mathrm{F}^{\prime} \mathrm{v} / \mathrm{F}^{\prime} \mathrm{m}$ is more sensitive than Fv/Fm. Our work also demonstrated the possibility of screening of in vitro grown plantlets for heat stress tolerance using chlorophyll fluorescence imaging system. On the other hand, in response to heat stress, the SOD activity was not affected for all hybrids and no significant difference among hybrids at different duration of exposure. Moreover, proline accumulation was observed at $6^{\text {th }}$ day of high temperature exposure only for $R$. 'XXL'.

\section{Acknowledgments}

This study was supported by Program of Science and Technology Talents Training in Yunnan Province (Grant No. 2016HA005), Applied Basic Research Project of Yunnan Province (Grant No. 2018BB010), Innovative Talent Development Project of Yunnan Province (Grant No. 2018HB082), and The Talented Young Scientist Program of China (Ethiopia - 18-002).

\section{References}

Aitken-Christie, J., Davies, H.E., Kubota, C., and Fujiwara, K. (1992). Effect of nutrient media composition on sugar-free growth and chlorophyll fluorescence of Pinus radiata shoots in vitro. Acta Hortic. 319, 125-128. https://doi.org/10.17660/ActaHortic.1992.319.14.

Anisko, T., and Lindstrom, O.M. (1996). Cold hardiness and water relations parameters in Rhododendron cv Catawbiense Boursault subjected to drought episodes. Physiol. Plant. 98, 147-155. https:// doi.org/10.1111/j.1399-3054.1996.tb00686.x.
Baker, N.R. (2008). Chlorophyll fluorescence: A probe of photosynthesis in vivo. Annu. Rev. Plant. Biol. 59, 89-113. https:// doi.org/10.1146/annurev.arplant.59.032607.092759.

Baker, N.R., and Rosenqvist, E. (2004). Applications of chlorophyll fluorescence can improve crop production strategies: An examination of future possibilities. J. Expt. Bot. 55, 1607-1621. https://doi.org/10.1093/jxb/erh196.

Bates, L.S., Waldren, R.P., and Teare, I.D. (1973). Rapid determination of free proline content for water-stress studies. Plant Soil 39, 205207. https://doi.org/10.1007/BF00018060.

Beauchamp, C., and Fridovich, I. (1971). Superoxide dismutase: improved assays and an assay applicable to acrylamide gels. Anal. Biochem. 44, 276-287. https://doi.org/10.1016/0003-2697(71)90370-8.

Bita, C.E., and Gerats, T. (2013). Plant tolerance to high temperature in a changing environment: scientific fundamentals and production of heat stress-tolerant crops. Front. Plant Sci. 4, 1-18. https://doi. org/10.3389/fpls.2013.00273.

Brestic, M., and Zivcak, M. (2013). PSII fluorescence techniques for measurement of drought and high temperature stress signal in plants: Protocols and applications. In Molecular Stress Physiology of Plants, G.R. Rout, and A.B. Das, eds. (Dordrecht: Springer), p. 87-131. https://doi.org/10.1007/978-81-322-0807-5_4.

Butler, W.L. (1978). Energy distribution in the photochemical apparatus of photosynthesis. Annu. Rev. Plant. Physiol. 29, 345-378. https://doi.org/10.1146/annurev.pp.29.060178.002021.

Cai, Y.F., Li, S.F., Xie, W.J., and Song, J. (2014). How do leaf anatomies and photosynthesis of three Rhododendron species relate to their natural environments? Bot. Stud. 55, 36-45. https://doi. org/10.1186/1999-3110-55-36.

Cai, Y.F., Wang, J.H., Zhang, L., Song, J., Peng, L.C., and Zhang, S.B. (2019). Physiological and transcriptomic analysis highlight key metabolic pathways in relation to drought tolerance in Rhododendron delavayi. Physiol. Mol. Biol. Plants 25, 991-1008. https://doi.org/10.1007/ s12298-019-00685-1.

Cordero, R.A., and Nilsen, E.T. (2002). Effects of summer drought and winter freezing on stem hydraulic conductivity of Rhododendron species from contrasting climates. Tree Physiol. 22, 919-928. https://doi.org/10.1093/treephys/22.13.919.

Cullen, J. (2005). Hardy Rhododendron species: A guide to identification (Oregon, U.S.A.: Timber Press Inc.).

De Ronde, J.A., Cress, W.A., Kruger, G.H.J., Strasser, R.J., and Van Staden, J. (2004). Photosynthetic response of transgenic soy bean plants, containing an Arabidopsis P5CR gene, during heat and drought stress. J. Plant. Physiol. 161, 1211-1224. https://doi.org/10.1016/j. jplph.2004.01.014.

Dobra, J., Motyka, V., Dobrev, P., Malbeck, J., Prasil, I.T., Haisel, D., Gaudinova, A., Havlova, M., Gubis, J., and Vankova, R. (2010). Comparison of hormonal responses to heat, drought and combined stress in tobacco plants with elevated proline content. J. Plant Physiol. 167,1360-1370. https://doi.org/10.1016/j.jplph.2010.05.013.

Fang, L., Tong, J., Dong, Y., Xu, D., Mao, J., and Zhou, Y. (2017). De novo RNA sequencing transcriptome of Rhododendron obtusum identified the early heat response genes involved in the transcriptional regulation of photosynthesis. PLoS ONE 12, e0186376. https://doi. org/10.1371/journal.pone.0186376.

Hameed, M., Keitel, C., Ahmad, N., Mahmood, T., and Trethowan, R. (2015). Screening of tomatoes germplasm for heat stress tolerance under controlled conditions. Proc. Environ. Sci. 29, 173-174. https:// doi.org/10.1016/j.proenv.2015.07.245.

Hussain, H.A., Men, S., Hussain, S., Chen, Y., Ali, S., Zhang, S., Zhang, K., Li, Y., Xu, Q., Liao, C., and Wang, L. (2019). Interactive effects of drought and heat stresses on morphophysiological attributes, yield, 
nutrient uptake and oxidative status in maize hybrids. Sci. Rep. 9, 3890. https://doi.org/10.1038/s41598-019-40362-7.

Ibaraki, Y., and Matsumura, K. (2005). Non distractive evaluation of the photosynthetic capacity of PSII in micropropagated plants. J. Agri. Meteor. 60, 1073-1076. https://doi.org/10.2480/agrmet.1073.

IPCC (2018). Summary for policymakers. In Global Warming of $1.5^{\circ} \mathrm{C}$. An IPCC Special Report on the impacts of global warming of $1.5^{\circ} \mathrm{C}$ above pre-industrial levels and related global greenhouse gas emission pathways, in the context of strengthening the global response to the threat of climate change, sustainable development, and efforts to eradicate poverty, V. Masson-Delmotte et al., eds. (Geneva, Switzerland: World Meteorological Org.), p. 3-7.

Kalaji, H.M., Jajoo, A., Oukarroum, A., et al. (2016). Chlorophyll a fluorescence as a tool to monitor physiological status of plants under abiotic stress conditions. Acta Physiol. Plant. 38, 102. https://doi. org/10.1007/s11738-016-2113-y.

Krebs, S.L. (2018a). Rhododendron. In Ornamental Crops, Handbook of Plant Breeding, J. Van Huylenbroeck, ed. (Cham: Springer), p. 673718. https://doi.org/10.1007/978-3-319-90698-0_26.

Krebs, S.L. (2018b). Heat-induced predisposition to Phytophthora root rots disease in Rhododendron. Acta Hortic. 1191, 59-68. https:// doi.org/10.17660/ActaHortic.2018.1191.9.

Lawson, T., and Vialet-Chabrand, S. (2018). Chlorophyll fluorescence imaging. In Photosynthesis: Methods and Protocols, S. Coushoff, ed. (New York: Humana Press), p. 121-140. https://doi. org/10.1007/978-1-4939-7786-4_8.

Lipp, C.C., and Nilsen, E.T. (1997). The impact of subcanopy light environment on the hydraulic vulnerability of Rhododendron maximum to freeze-thaw cycles and drought. Plant Cell Environm. 20, 1264-1272. https://doi.org/10.1046/j.1365-3040.1997.d01-22.x.

Lv, W.T., Lin, B., Zhang, M., and Hua, X.J. (2011). Proline accumulation is inhibitory to Arabidopsis seedlings during heat stress. Plant Physiol. 156, 1921-1933. https://doi.org/10.1104/pp.111.175810.

Marian, C.O., Eris, A., Krebs, S.L., and Arora, R. (2004). Environmental regulation of a $25 \mathrm{kDa}$ Dehydrin in relation to Rhododendron cold acclimation. J. Am. Soc. Hortic. Sci. 129, 354-359. https://doi. org/10.21273/JASHS.129.3.0354.

Mathur, S., and Jajoo, A. (2014). Photosynthesis: Limitations in response to high temperature stress. J. Photochem. Photobiol. B. Biol. 137, 116-126. https://doi.org/10.1016/j.jphotobiol.2014.01.010.

Oxborough, K. (2004). Imaging of chlorophyll a fluorescence: theoretical and practical aspects of an emerging technique for the monitoring of photosynthetic performance. J. Expt. Bot. 55, 11951205. https://doi.org/10.1093/jxb/erh145.

Quint, M., Delker, C., Franklin, K.A., Wigge, P.A., Halliday, K.J., and Van Zanten, M. (2016). Molecular and genetic control of plant thermomorphogenesis. Nat. Plants 2, 15190. https://doi. org/10.1038/nplants.2015.190.

Rai, M.J., Kalia, R.K., Singh, R., Gangola, M.P., and Dhawan, A.K. (2011). Developing stress tolerant plants through in vitro selection - An overview of the recent progress. Environ. Expt. Bot. 71, 89-98. https://doi.org/10.1016/j.envexpbot.2010.10.021.

Raja, V., Qadir, S.U., Alyemeni, M.N., and Ahmad, P. (2020). Impact of drought and heat stress individually and in combination on physio-biochemical parameters, antioxidant responses, and gene expression in Solanum lycopersicum. 3 Biotech. 10, 208. https://doi. org/10.1007/s13205-020-02206-4.

Ranney, T.G., Blazich, F.A., and Warren, S.L. (1995). Heat tolerance of selected species and populations of Rhododendron. J. Amer. Soc. Hortic. Sci. 120, 423-428. https://doi.org/10.21273/ JASHS.120.3.423.
Rizhsky, L., Liang, H.J., Shuman, J., Shulaev, V., Davletova, S., and Mittler, R. (2004). When defense pathways collide. The response of Arabidopsis to a combination of drought and heat stress. Plant Physiol. 134, 1683-1696. https://doi.org/10.1104/pp.103.033431.

Serret, M.D., Trilas, M.I., and Araus, J.L. (2001). The effect of in vitro culture conditions on the pattern of inhibition during acclimation of gardenia to ex vitro conditions. Photosynthetica 39, 67-73. https:// doi.org/10.1023/A:1012443919022.

Shen, H., Zhao, B., Xu, J., Zheng, X., and Huang, W. (2016). Effects of salicylic acid and calcium chloride on heat tolerance in Rhododendron 'Fen Zhen Zhu'. J. Am. Soc. Hortic. Sci. 141, 363-372. https://doi. org/10.21273/JASHS.141.4.363.

Shen, H.F., Zhao, B., Xu, J.J., Liang, W., Huang, W.M., and Li, H.H. (2017). Effects of heat stress on changes in physiology and anatomy in two cultivars of Rhododendron. South African J. Botany 112, 338-345. https://doi.org/10.1016/j.sajb.2017.06.018.

Singh, D., Singh, C.K., Taunk, J., Jadon, V., Pal, M., and Gaikwad, K. (2019). Genome wide transcriptome analysis reveals vital role of heat responsive genes in regulatory mechanisms of lentil (Lens culinaris Medikus). Sci. Rep. 9, 1-9. https://doi.org/10.1038/ s41598-019-49496-0.

Song, S.Q., Lei, Y.B., and Tian, X.R. (2005). Proline metabolism and cross-tolerance to salinity and heat stress in germinating wheat seeds. Russ. J. Plant. Physiol. 52, 793-800. https://doi.org/10.1007/ s11183-005-0117-3.

Theis, J., and Schroda, M. (2016). Revisiting the photosystem II repair cycle. Plant Signal. Behav. 11, e1218587. https://doi.org/10.1080/1 5592324.2016.1218587.

Van Nocker, S., and Gardiner, E.E. (2014). Breeding better cultivars, faster: applications of new technologies for the rapid deployment of superior horticultural tree crops. Hortic. Res. 1, 14022. https://doi. org/10.1038/hortres.2014.22.

Vollenweider, P., and Günthardt-Goerg, M.S. (2005). Diagnosis of abiotic and biotic stress factors using the visible symptoms in foliage. Environm. Pollut. 137, 455-465. https://doi.org/10.1016/j. envpol.2005.01.032.

Wahid, A., Gelani, S., Ashraf, M., and Foolad, M.R. (2007). Heat tolerance in plants: An overview. Environm. Expt. Bot. 61, 199-223. https://doi.org/10.1016/j.envexpbot.2007.05.011.

Waszczak, C., Carmody, M., and Kangasjärvi, J. (2018). Reactive oxygen species in plant signaling. Annu. Rev. Plant. Biol. 69, 209-236. https://doi.org/10.1146/annurev-arplant-042817-040322.

Zhao, Y., Yu, W., Hu, X., et al. (2018). Physiological and transcriptomic analysis revealed the involvement of crucial factors in heat stress response of Rhododendron hainanense. Gene 660, 109-119. https:// doi.org/10.1016/j.gene.2018.03.082.

Zhou, R., Kong, L., Yu, X., Ottosen, C., Zhao, T., Jiang, F., and Wu, Z. (2019). Oxidative damage and antioxidant mechanism in tomatoes responding to drought and heat stress. Acta Physiol. Plant. 41, 1-11. https://doi.org/10.1007/s11738-019-2805-1.

Received: Jan. 12, 2020

Accepted: Jul. 28, 2020

Addresses of authors:

Elias Gebremariam $\mathrm{Oba}^{1,2}$, Jingfeng $\mathrm{Hu}^{3}$, Zhihui Zhang ${ }^{4}$, Shifeng Li ${ }^{1}$, Lvchun Peng ${ }^{1}$, Jihua Wang ${ }^{1}$ and Weijia Xie ${ }^{1, *}$ ${ }^{1}$ Flower Research Institute of Yunnan Academy of Agricultural Science, National Engineering Research Center for Ornamental Horticulture, Kunming, Yunnan 650205, PR China 
${ }^{2}$ Ethiopian Institute of Agricultural Research, P.O. Box 2003, Addis Ababa, Ethiopia

${ }^{3}$ Institute of Horticultural Crops of Yunnan Academy of Agricultural Science, Kunming, Yunnan 650205, PR China

${ }^{4}$ Institute of Medicinal Plant of Yunnan Academy of

Agricultural Science, Kunming, Yunnan 650205, PR China

* Corresponding author; E-mail: weijiax@163.com 